\title{
Retinopathy of prematurity in Ardabil, North West of Iran: Prevalence and risk factors
}

\author{
Yousef Fekri (1), Habib Ojaghi (1), Neda Momeni (2), Firouz Amani (2)
}

(1)Department of Surgery, School of Medicine and Allied Medical Sciences, Imam Reza Hospital, Ardabil University of Medical Sciences, Ardabil, Iran; (2) School of Medicine, Ardabil University of Medical Sciences, Ardabil, Iran.

This article is distributed under the terms of the Creative Commons Attribution Noncommercial License (CC BY-NC 4.0) which permits any noncommercial use, distribution, and reproduction in any medium, provided the original author(s) and source are credited.

\begin{abstract}
Retinopathy of prematurity (ROP), which affects the retina of premature infants, is a leading cause of blindness in premature infants worldwide. The aim of this study was to evaluate the frequency and risk factors of retinopathy of prematurity infants referred to Alavi hospital between October 2018 and October 2019. In the present study, 400 infants with gestational age less than 34 weeks and or birth weight of $2000 \mathrm{~g}$ or less were enrolled in the study. Required information including sex, gestational age, maternal age, birth weight, type of delivery, oxygen therapy, septicemia, multiple gestations, consanguineous marriage, respiratory problem, and blood exchange were extracted from their hospital records and then included in the data collection form. These infants were also examined for ROP, stage and area of involvement by an experienced ophthalmologist and then classified into two groups including retinopathy and healthy group. Finally, the data were analyzed in SPSS 25 software using chi-square, fisher exact test, t-test, binary logistic regression, and ROC curve analysis. Of the 400 preterm infants studied (57.2\% male and 42.8\% female), 107 (26.8\%) infants had ROP of whom 23 (21.5\%) needed treatment (i.e. 5.8\% of all infants need treatment). There were 4 (3.7\%), 29 (27.1\%), and 74 (69.2\%) infants with zone I, II, and III, respectively. There were 91 (85\%), 11 (10.3\%), and 5 (4.7\%) infants with stage I, II, and III, respectively. Multivariate logistic regression analysis showed that parental consanguinity $(\mathrm{OR}=2.263,95 \% \mathrm{CI}$ : $1.240-4.130, \mathrm{P}=0.008)$, gestational age less than 32.5 weeks (OR=4.067, 95\%CI: 2.340-7.069, $\mathrm{P}<0.001)$, and birth weight less than 1725 g $(\mathrm{OR}=4.522$, 95\%CI: 2.677-7.637, $\mathrm{P}<0.001)$ were associated with a 2.3-fold, 4.1-fold, and 4.5fold increased risk of ROP, respectively. ROP had no significant relationship with other variables. In summary, the findings of the present study showed that one quarter of the premature infants had ROP. Furthermore, birth weight less than 1725 g, gestational age less than 32.5 weeks, and parental consanguinity were risk factors for ROP, in addition, one-fifth of the infants with ROP needed treatment.
\end{abstract}

Key Words: Retinopathy; prematurity; ROP; newborn.

Eur J Transl Myol 31 (4): 10063, 2021 doi: 10.4081/ejtm.2021.10063

Retinopathy of prematurity (ROP) is a proliferative retinopathy that affects the retinal blood vessels in preterm and low birth weight infants and is one of the most important and preventable diseases of pediatric blindness. $^{1,2}$ It is a type of two-stage proliferative retinopathy that occurs in premature infants due to the arrest of normal retinal neuronal and vascular development. ${ }^{3}$ The results of many studies show that this disease is multifactorial and is associated with risk factors such as low birth weight, low intrauterine age, oxygen therapy during hospitalization in neonatal intensive care unit, respiratory problems, sepsis and multi parity. However, the causal relationship of these factors has not been definitively confirmed, because some researchers consider this disease to be dependent on geographical area and health facilities. ${ }^{4}$ Infants weighing less than 1,500 grams are at high risk for ROP, together with lower gestational age. ${ }^{1,5}$ In poor countries with an infant mortality rate of more than 60 per 1,000 live births, a small number of premature infants survive due to lack of NICU facilities, thus ROP is very rare in these countries. Conversely, in countries where infant mortality rates are less than 10 per 1,000 live births, ROP is responsible for $6-20 \%$ of blindness. In countries where this death rate is in the range between the above two rates, such as Iran, ROP is a main cause of blindness in 


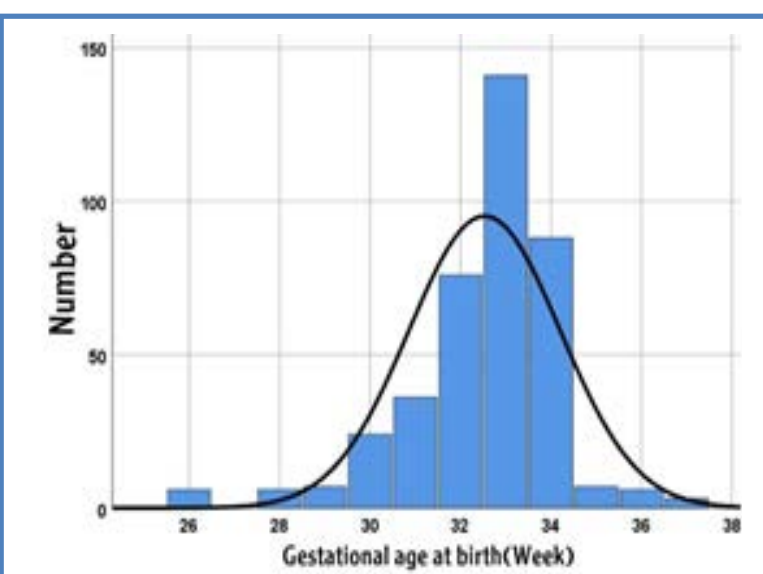

Fig 1. Histogram of gestational age at birth.

children. ${ }^{1}$ In 2010, it was estimated that out of 32,700 infants with ROP, 6,300 needed treatment in highincome countries, and 1,700 infants developed blindness or severe visual impairment. ${ }^{6}$ In the United States, ROP is the second most common cause of blindness in children after cerebral cortical blindness. ${ }^{7}$ The prevalence of ROP in infants weighing less than 1,251 grams in the United States is reported to be $68 \%{ }^{8}$ According to available data, the prevalence of ROP has increased in developing countries, which refers to the third epidemy of ROP. There are several causes for this epidemic, such as high birth rates, especially premature births in these countries, and low neonatal care facilities. Iran is considered one of the countries with a high prevalence of ROP. ${ }^{2}$ Treatment began in the late 1980s and the first treatment used for ROP was cryotherapy, and recently lasers have been used to treat ROP, which seems to have been more effective. ${ }^{3}$ In addition to severe visual impairment, infants with ROP are also exposed to other disabilities due to brain injury including motor disorders, decreased educational performance, and quality of life. ${ }^{9}$ Though, the disease regresses spontaneously in $80 \%$ of cases, this does not prevent late complications such as myopia with astigmatism, strabismus and amblyopia. Final complication of the disease is blindness. ${ }^{4}$ It is estimated that ROP causes worldwide 50000 annual cases of blindness in children. ${ }^{3}$ In the present study, an attempt was made to identify the frequency of this disease and its possible risk factors by examining premature infants born in Alavi Hospital, Ardabil, Iran. Therefore, pediatricians and ophthalmologists need to be warned of the importance of prevention through screening and more accurate assessment of ROP.

\section{Materials and Methods}

In this case series study, all 400 premature infants referred to the eye clinic of Alavi Hospital from October 2018 to October 2019 who met the criteria were included in the study. Sampling was by census method. The study

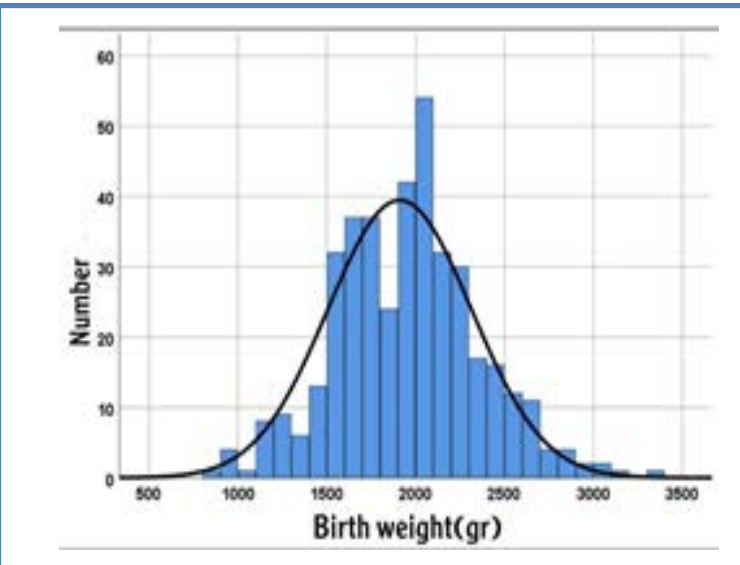

Fig 2. Histogram of birth weight.

and consent procedure were approved by the Ardabil University of Medical Sciences Ethics committee (IR ARUMS.REC.1398.308) and the tenets of Declaration of Helsinki were followed in all steps of the study.

Inclusion criteria included infants with a gestational age of less than 34 weeks (33 weeks and 6 days or less) or with a birth weight of $2000 \mathrm{~g}$ or less. Exclusion criteria was the parents' unwillingness to participate in the study. The pupil was dilated by using mydriatic drops about an hour before the examination to make the examination possible. To perform this method, a combination of tetracaine drops (0.5\%), tropicamide (1\%) and phenylephrine $(2.5 \%)$ (with a combination of one-half volume of each) was used 2 to 3 times at intervals of 10 to 15 minutes. Indirect ophthalmoscopy was performed with or without blepharostat. All retinal examinations were performed by an experienced ophthalmologist (Fekri) who had completed the ROP training course.

Ambient brightness was reduced to 10 lux when the baby was examined. Data were collected through detailed checklists. The designed checklists contained demographic information and risk factors that were completed for all patients. Finally, individuals were divided into 2 groups (positive retinopathy group and healthy group). After completing the checklists for all participants, the data were coded and entered into SPSS 25 software.

\section{Data analysis}

After data collection, central indices (mean) and dispersion indices (standard deviation) were used to analyze descriptive information. Chi-square, Fisher exact, t-test, binary logistic regression and ROC curve analysis in SPSS software version 25 were used to analyze the data. $\mathrm{P}$ value less than 0.05 was considered significant.

\section{Results}

In the present study, the mean age of the mothers was 28.9 \pm 6.5 years (Range: 14-53 years). Furthermore, 81 cases $(20.2 \%)$ of marriages were consanguineous and 
Table 1. Relationship between $R O P$ and quantitative variables.

\begin{tabular}{|l|l|l|l|}
\hline \multirow{2}{*}{ Parameters } & \multicolumn{2}{|l|}{ ROP } & \multirow{2}{*}{ P-Value } \\
\cline { 2 - 4 } & $\begin{array}{l}\text { positive } \\
(\mathbf{n = 1 0 7})\end{array}$ & $\begin{array}{l}\text { negative } \\
(\mathbf{n = 2 9 3 )}\end{array}$ & $\mathrm{P}<0041$ \\
\hline $\begin{array}{l}\text { Mother age (years) } \\
\text { Mean } \pm \text { SD }\end{array}$ & $27.8 \pm 59$ & $29.3 \pm 6.7$ & $\mathrm{P}<0.001$ \\
\hline $\begin{array}{l}\text { Gestational.age (weeks) } \\
\text { Mean } \pm \text { SD }\end{array}$ & $31.4 \pm 200$ & $33 \pm 13$ & $\mathrm{P}<0.001$ \\
\hline $\begin{array}{l}\text { Birth-weight (gram) } \\
\text { Mean } \pm \text { SD }\end{array}$ & $1628 \pm 324.8$ & $2012.7 \pm 381.1$. & \\
\hline
\end{tabular}

ROP: Retinopathy of prematurity; SD:Standard Deviation

319 cases (79.8\%) were non-consanguineous. In addition, 116 cases (29\%) of pregnancies were twins and 284 cases (71\%) were single. As shown in Figure 1, the mean gestational age at birth was $32.5 \pm 1.7$ weeks (Range: 26-37 weeks). Of the 400 neonates, 229 neonates (57.2\%) were male and 171 neonates (42.8\%) were female 297 cases (74.2\%) belonged to cesarean deliveries and 103 cases (25.8\%) to normal vaginal deliveries. The average birth weight of infants was $1909.8 \mathrm{gr} \pm 404.2$ (Range: 580-3300 gr; Figure 2). Of the 400 neonates, 395 (98.8\%) had undergone oxygen therapy and blood transfusions were performed for 4 neonates (1\%). Moreover, 1 case $(0.3 \%)$ had sepsis and 277 patients
(69.3\%) had respiratory problems. Out of 400 premature infants studied, 107 infants (26.8\%) had retinopathy. Out of 107 preterm infants with retinopathy, 4 infants (3.7\%) showed Zone I involvement, followed by Zone II (29 infants; 27.1\%), and Zone III (74 infants; 69.2\%). Furthermore, 91 infants (85\%) showed stage I, followed by stage II (11 infants; 10.3\%), and stage III (5 infants; $4.7 \%)$.

Of the 107 preterm infants with ROP, 23 (21.5\%) needed treatment. Table 1 shows the relationship between retinopathy and maternal age, gestational age, and birth weight. Table 2 shows the association between ROP and consanguineous marriage, twins, infant gender, type of

Table 2. Relationship between ROP and quantitative variables (B).

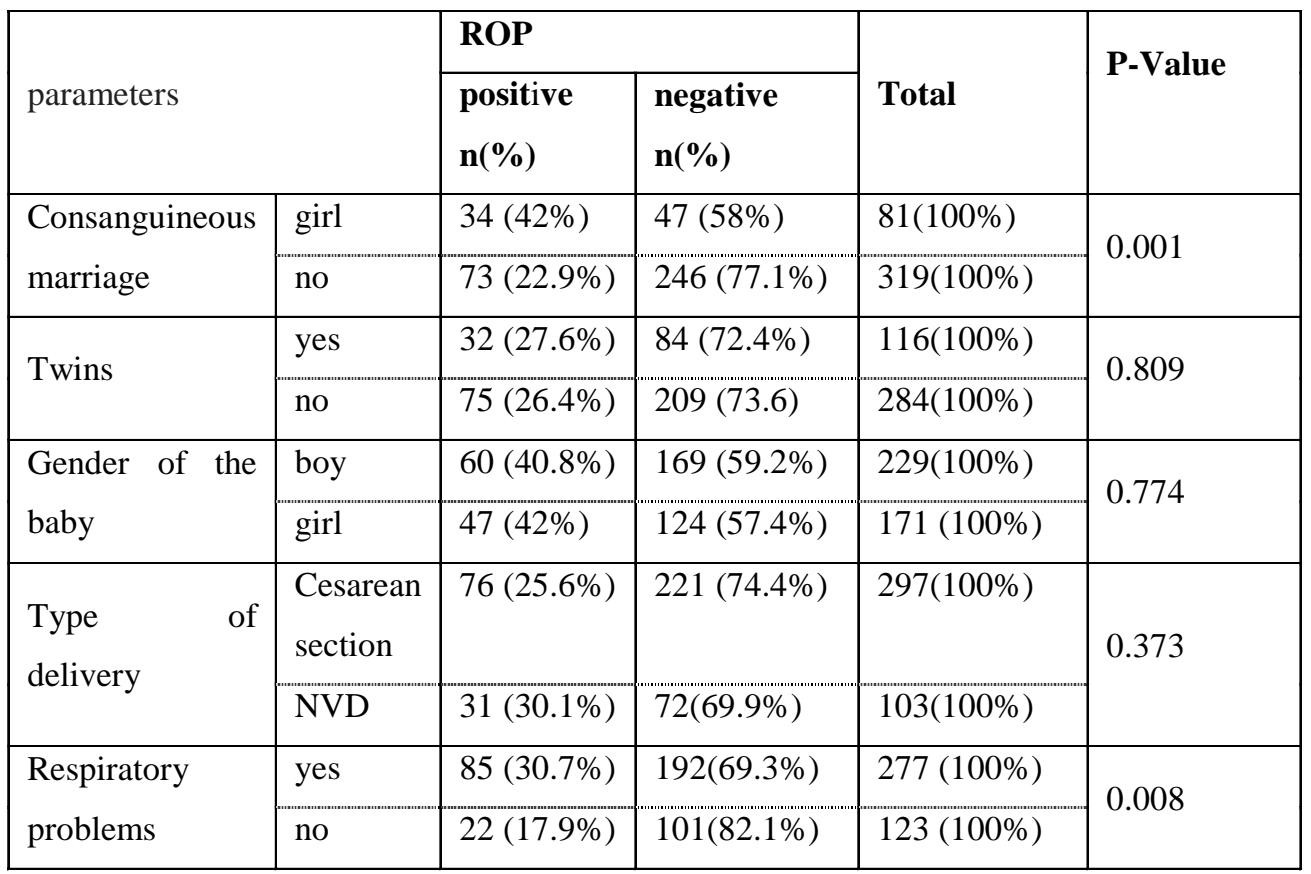

R0P: Retinopathy of prematurity; SD:Standard Deviation; NVD: Normal Vaginal Delivery 


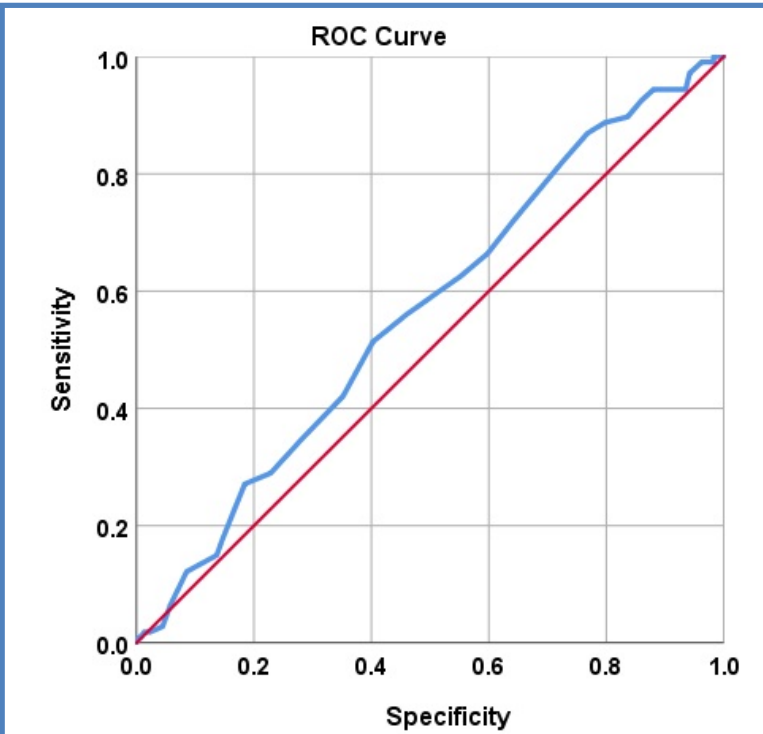

Fig 3. ROC analysis to determine the risk of ROP by maternal age.

delivery, oxygen therapy, and respiratory problems. As it shown, retinopathy in infants was significantly associated with maternal age $(\mathrm{P}=0.041)$, gestational age ( $\mathrm{P}<0.001)$, birth weight $(\mathrm{P}<0.001)$, parental consanguineous marriage $(\mathrm{P}=0.001)$, and respiratory problems ( $\mathrm{P}=0.008)$. Out of 400 premature infants, 395 infants $(98.8 \%)$ received oxygen therapy. Only 4 neonates (1\%) had blood transfusions, and only 1 neonate (0.3\%) developed septicemia. It was practically impossible to calculate the relationship between retinopathy of prematurity in these three variables in this study. Receiver Operating Characteristic (ROC) curve was used to determine the optimal cut-off value for maternal age and to predict the risk of developing preterm infants with retinopathy (Figure 3 ). The area under the

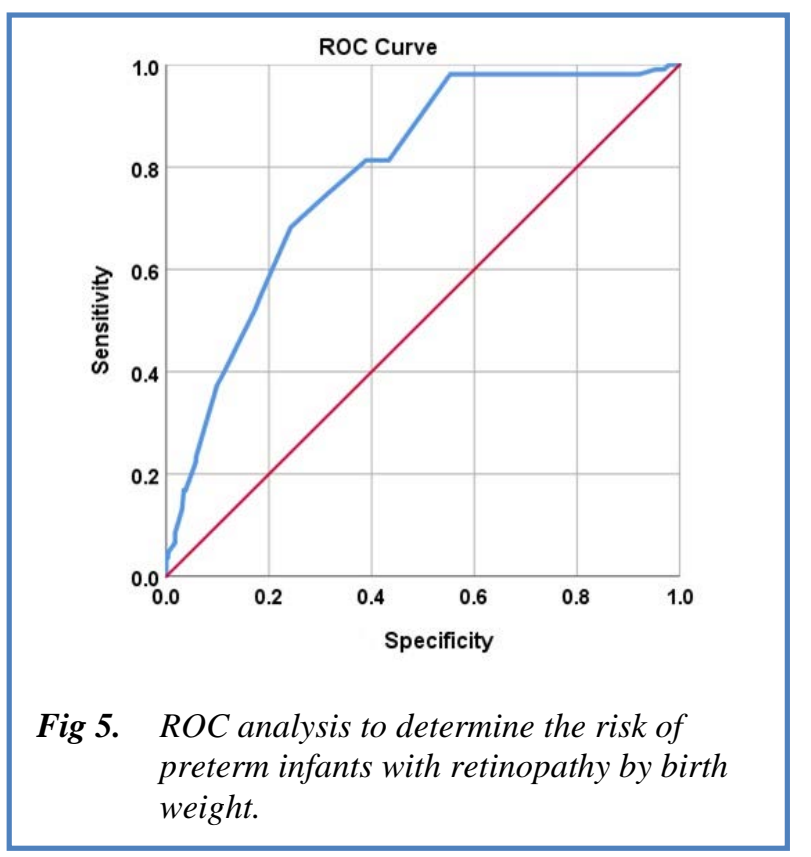

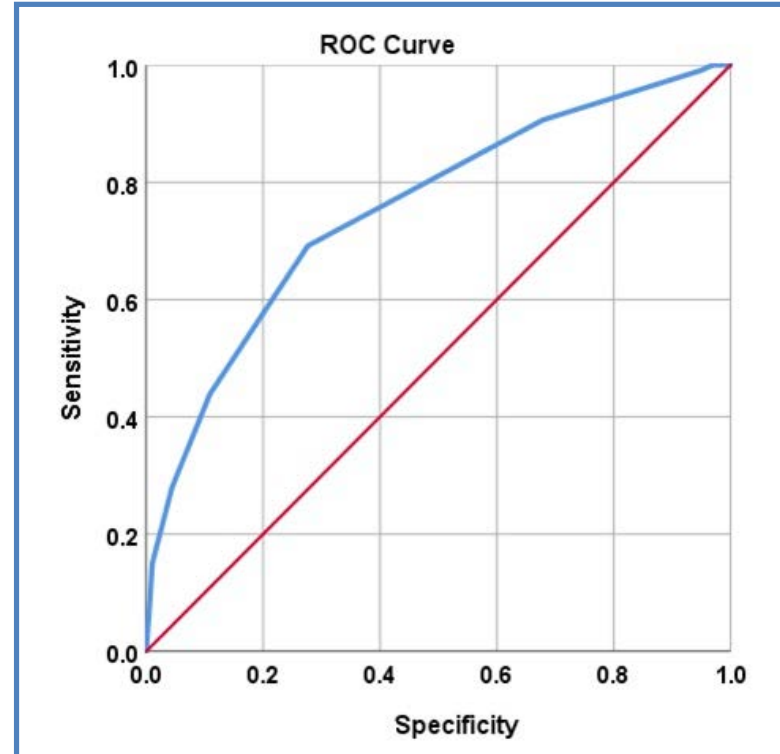

Fig 4. ROC analysis to determine the risk of ROP by gestional age.

ROC curve was $56.4 \%$ and the best cut-off value for gestational age was obtained to predict ROP at 27.5 years (with $51 \%$ sensitivity and $60 \%$ specificity). Thus, age less than 27.5 years for the mother during pregnancy increased the risk of ROP by about 1.6 times (OR = 1.569, 95\% CI: 1.005-2.448, $\mathrm{P}=0.047$ ). Based on the data presented in Figure 4, the area under the ROC curve was $75.5 \%$ and the best cut-off value for gestational age to predict premature neonatal retinopathy was 32.5 weeks (sensitivity of $69 \%$ and specificity of $72 \%$ ). Having a gestational age of less than 32.5 weeks at birth increased the risk of ROP by about 5.9 times (OR $=5.869,95 \% \mathrm{CI}$ : 3.619-9.519, $\mathrm{P}<0.001)$. Also the area under the ROC curve was $78.7 \%$ and the best cut-off value for birth weight to predict ROP was 1725 gr (sensitivity of $68 \%$

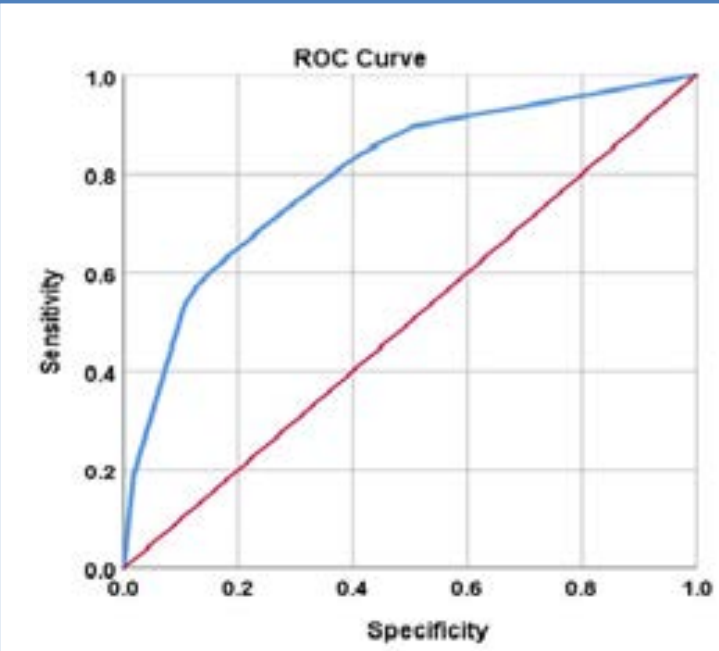

Fig 6. ROC analysis to determine the risk of preterm infants with retinopathy by week of birth, birth weight, and familial parental marriage. 
Retinopathy of prematurity: prevalence and risk factors

Eur J Transl Myol 31 (4): 10063, 2021 doi: 10.4081/ejtm.2021.10063

\begin{tabular}{|c|c|c|c|c|c|c|c|}
\hline \multirow[b]{3}{*}{ Dependent outcome } & \multirow{3}{*}{$\begin{array}{l}\text { Independent } \\
\text { variable }\end{array}$} & \multirow[b]{3}{*}{ Estimation } & \multirow[b]{3}{*}{$\begin{array}{l}\text { Standard } \\
\text { error }\end{array}$} & \multirow[b]{3}{*}{ Risk ratio } & \multirow{2}{*}{\multicolumn{2}{|c|}{ 95\% confidence interval }} & \multirow[b]{3}{*}{$\mathrm{p}$-Value } \\
\hline & & & & & & & \\
\hline & & & & & $\begin{array}{l}\text { Lower } \\
\text { bound }\end{array}$ & $\begin{array}{l}\text { Upper } \\
\text { bound }\end{array}$ & \\
\hline \multirow{6}{*}{ Retinopathy } & Parental marriage & 0.817 & 0.307 & 2.263 & 1.240 & 4.130 & 0.008 \\
\hline & $\begin{array}{l}\text { Mother age less } \\
\text { than } 27.5 \text { years } \\
\end{array}$ & 0.415 & 0.266 & 1.514 & 0.899 & 2.549 & 0.119 \\
\hline & $\begin{array}{l}\text { Birth.week less } \\
\text { than } 32.5 \text { weeks }\end{array}$ & 1.403 & 0.282 & 4.067 & 2.340 & 7.069 & $\mathrm{P}<0.001$ \\
\hline & $\begin{array}{l}\text { Birth.weight less } \\
\text { than } 1725 \text { grams }\end{array}$ & 1.509 & 0.267 & 4.522 & 2.677 & 7.637 & $\mathrm{P}<0.001$ \\
\hline & $\begin{array}{l}\text { Existence of } \\
\text { respiratory } \\
\text { problems }\end{array}$ & 0.020 & 0.318 & 1.020 & 0.547 & 1.901 & 0.950 \\
\hline & constant & -2.764 & 0.330 & 0.063 & & & \\
\hline
\end{tabular}

and specificity of 76\%; Figure 5). Weighing less than 1725 gr at birth increased the risk of ROP by about 6.7 times (OR $=6.713,95 \% \mathrm{CI}: 4.126-10.924, \mathrm{P}<0.001)$. Binary logistic regression analysis was used to determine the risk factors for retinopathy in this study. In this analysis, "infant retinopathy" entered the model as a dependent variable and the independent variables were: (1) familial marriage of parents, (2) mother age less than 27.5 years, (3) week of birth less than 32.5 weeks, (4) birth weight less than 1725 grams, and (5) breathing problems of the baby (Table 3). As shown in table 3, familial marriage, birth week less than 32.5 weeks, and birth weight less than 1725 grams were the risk factors for ROP.

Familial marriage was associated with a 2.3-fold increase in the risk of ROP (OR $=2.263$, 95\% CI: 1.240-4.130, P $=0.008$ ). Birth week less than 32.5 weeks was associated with a 4.1-fold increase in the risk of ROP (OR $=4.067$, 95\% CI: 2.340-7.069, P <0.001). Birth weight less than $1725 \mathrm{~g}$ was associated with a 4.5-fold increase in the risk of ROP (OR $=4.522,95 \%$ CI: 2.677-7.637, $\mathrm{P}<0.001$ ). But the mother's age was less than 27.5 years and the presence of respiratory problems in the infant did not show a significant relationship with ROP. Calculating the combined risk ratio of ROP i.e., estimating the risk ratio of retinopathy in preterm infants who had all three risk factors (familial parental marriage + birth week less than 32.5 + birth weight less than 1725 gr) showed that premature infants who had all three of these risk factors were about 52.7 times more likely to develop retinopathy as compared with infants without these risk factors (OR $=52.727,95 \%$ CI: 16.597-167.507, P <0.001). Figure 6 also shows the corresponding ROC curve, which had an area under curve of $79.9 \%$.

\section{Discussion}

In the present study, 107 neonates (26.8\%) of the 400 preterm infants had ROP.The prevalence of ROP varies greatly in different studies. Among studies conducted outside Iran, the prevalence of ROP in the study of Chedid et al. (2009) in the UAE was $11 \%$, followed by $15.2 \%$ in the study of Kossambe et al. (2019) in India, and $19.9 \%$ in the study of Ludwig et al. (2017) in the United States, all of which are less than our study. ${ }^{10-12}$ While its prevalence in the study of Acevedo-castelln et al. (2019) in Mexico was 56.1\%, followed by $40.4 \%$ in Oman, 34\% in Egypt, 33\% in Pakistan, and 31.3\% in Portugal. All are more than the present study. ${ }^{13-17}$ The prevalence of ROP in Saudi Arabia has been reported to be $28 \%$, which is similar to our findings. ${ }^{18}$ Studies in Iran also show a large difference in the prevalence reported for ROP. In the study of Daraie et al. (2015) in Semnan,

Table 4. Comparison of the results of the present study with studies conducted in other countries.

\begin{tabular}{|c|c|c|c|c|}
\hline Study & $\begin{array}{l}\text { Gestational } \\
\text { age(week) }\end{array}$ & Birth weight of Newborn (grams) & Sample size & ROP frequency \\
\hline Mexico (2019) & Less than 34 & Less than 1750 & 132 & $56.1 \%$ \\
\hline Oman (2017) & Less than 32 & Less than 2000 & 171 & $40.4 \%$ \\
\hline Egypt (2013) & Less than 32 & Less than 1250 & 152 & $34 \%$ \\
\hline Pakistan (2019) & Less than 40 & Less than 2000 & 60 & $33 \%$ \\
\hline Portugal (2017) & Less than 32 & Less than 2000 & 527 & $31.3 \%$ \\
\hline Saudi Arabia (2011) & Less than 36 & Less than 1500 & 186 & $28 \%$ \\
\hline Current study & Less than 34 & Less than 2000 & 400 & $26.8 \%$ \\
\hline America (2017) & Less than 36 & Less than 2000 & 10.483 & $19.9 \%$ \\
\hline India (2019) & Less than 34 & Less than 1500 & 244 & $15.2 \%$ \\
\hline United Arab Emirates (2009) & Less than 34 & Less than 1750 & 175 & $11 \%$ \\
\hline
\end{tabular}


Retinopathy of prematurity: prevalence and risk factors

Eur J Transl Myol 31 (4): 10063, 2021 doi: 10.4081/ejtm.2021.10063

Table 5. Comparison of the results of the present study with studies conducted in Iran.
\begin{tabular}{|l|l|l|l|l|}
\hline Study & Gestational age(week) & Birth weight of Newborn(grams) & Sample size & ROP frequency \\
\hline Tehran (2008) & 37 or less & Less than 2000 & 953 & $34.5 \%$ \\
\hline Tehran (2007) & Less than 32 & Less than 1500 & 147 & $29.9 \%$ \\
\hline Kerman (2011) & Less than 36 & Less than 2500 & 83 & $29 \%$ \\
\hline Current study & Less than 34 & Less than 2000 & 400 & $26.8 \%$ \\
\hline Babol (2010) & Less than 37 & Less than 2000 & 173 & $19 \%$ \\
\hline Isfahan (2010) & Less than 36 & Less than 2000 & 604 & $17.5 \%$ \\
\hline Tabriz (2008) & Less than 36 & Less than 2000 & 150 & $17.3 \%$ \\
\hline Gorgan (2009) & Less than 34 & Less than 2000 & 89 & $5.6 \%$ \\
\hline Semnan(2015) & Less than 37 & Less than 2000 & 270 & $1.1 \%$ \\
\hline
\end{tabular}

a prevalence of $1.1 \%$ has been reported, followed by $5.6 \%$ in Gorgan, $17.3 \%$ in Tabriz, $17.5 \%$ in Isfahan, and $19 \%$ in Babol $(4-5,19-21)$ which are all less than the present study. (19.2\% vs $1.9 \%$; $\mathrm{p}=0.007) .{ }^{19-21}$ While this rate was reported as $34.5 \%$ in the study of Karkhaneh et al. (2008) in Tehran which is higher than the present study. ${ }^{22}$ Also, the prevalence of retinopathy of preterm infants in the study of Ghasemi Nejad et al. (2011) in Kerman was 29\% and in the study of Mansouri et al. (2007) in Tehran was 29.9\%, which is similar to our findings. ${ }^{23,24}$ Several factors, including the difference between the samples in terms of week of birth and birth weight, differences in disease severity; differences in available standards, facilities and strategies used to manage premature infants and many other factors can affect the results of different studies. For example, Daraei et al. (2015) attributed the very low prevalence of retinopathy of preterm infants to factors such as the lack of survival of infants with very young gestational age and with extremely low weight or appropriate oxygen therapy in the neonatal intensive care unit. ${ }^{19}$ For convenience of comparison, the results of different studies are summarized in Tables 4 and 5. Overall, due to the high prevalence of ROP in the present study (one in 4 preterm infants), it is necessary to inform more parents to go to diagnostic and treatment centers for timely examination of the retina of premature infants before retinopathy leads to permanent destruction. The most common stage of ROP in the present study was stage I (85\%); In addition, about $10 \%$ of infants had stage II retinopathy and $5 \%$ had stage III, and no cases of higher stages of the disease were observed among the preterm infants in this study. In the study of Ali et al. (2019) in Pakistan, ${ }^{16}$ like the present study, the majority of neonates had stage I ROP, but its frequency was lower than in our study (55\% VS 85\%) and the frequency of stage II and III retinopathy in preterm infants was higher than our study (35\% vs 10\%). No case of stage 4 or higher retinopathy was seen in their study. However, in the study of Coutinho et al. (2017) in Portugal, ${ }^{17}$ stage I and II retinopathies had almost the same prevalence (35.8\% vs $36.9 \%$ ) and the prevalence of stage III retinopathy has been higher than the present study ( $26.1 \%$ vs $5 \%$ in our study). In addition, in their study, $1.2 \%$ of preterm infants had stage IV retinopathy, but as mentioned, we did not have a case of stage 4 or higher. In the study of Fooladi Nejad et al. (2009) in Gorgan, ${ }^{20}$ retinopathy was seen in all premature infants in stage I disease, which is different from our findings. In terms of retinal zone involvement, zone III with a frequency of about $70 \%$ had the highest retinal involvement zone in our study, followed by zone II (with a frequency of about 27\%) and zone I (4\%). In the study by Acevedo-Castelln et al. (2019) in Mexico, (13) the most common zone of retinal involvement was in zone II (3\%), followed by zone III (31.1\%) and zone I (6.6\%) Which in this respect is not consistent with our observations. The findings of the present study showed that gestational age at birth had a statistically significant relationship with premature retinopathy, so that the week of birth of preterm infants with retinopathy was significantly lower than non-preterm infants (31.4 \pm 2 vs $33 \pm .1 .3$; $\mathrm{P}<0.001)$. Multivariate logistic regression analysis also confirmed this significant association, so that gestational age less than 32.5 weeks at birth increased the risk of retinopathy in our preterm infants by 4.1 times (OR $=4.067,95 \% \mathrm{CI}$ : 2.340-7.069, $\mathrm{P}<0.001$ ). ROP is a multifactorial disease in which low gestational age at birth has been suggested in several studies as an important risk factor for this disease. In studies in India, Pakistan, Mexico, Portugal, Oman, and Isfahan, the gestational age of neonates with retinopathy at birth was significantly lower than that of non-patients, 4,11,13,14,16,17 which are in accordance with our findings. In a study by Ludwig et al. (2017) in the United States, multivariate regression analysis showed that gestational age was an independent predictor of ROP, ${ }^{12}$ which is similar to the present study.

In a study conducted by Daraei et al. (2015) in Semnan, no significant relationship was observed between gestational age and the incidence of ROP, which is not consistent with the present study. ${ }^{19}$ The superficial vessels of the retina begin to develop from about the 14th week of the embryo and the deep vessels of the retina are formed around the 20th week through the germination of the previously formed vessels. And these vessels are completed on the nasal side of the retina at 36 weeks and on the temporal side at 40 weeks; Therefore, it seems that the birth of infants at a lower gestational age plays a role 
in the development of retinopathy by disrupting the natural process of retinal angiogenesis. ${ }^{9}$

Another factor associated with ROP in the present study was birth weight so that the birth weight of neonates with retinopathy was significantly lower than that of nonretinopathies (1628 \pm 324.8 vs $2012.7 \pm 381.1$; $\mathrm{P}<0.001)$. A significant relationship between birth weight and ROP was also confirmed by multivariate logistic regression analysis by which birth weight less than $1725 \mathrm{~g}$ was associated with a 4.5 -fold increase in the risk of ROP (OR $=4.522$, 95\% CI: 2.677-7.637, $\mathrm{P}<0.001)$. This finding is consistent with many previous studies.,11-13,16,17,19

An interesting finding in the present study, which even in multivariate logistic regression analysis was significantly associated with retinopathy in our preterm infants, was consanguineous marriage. The prevalence of preterm infant retinopathy in consanguineous marriages was significantly higher than non-consanguineous marriages (42\% vs. $22.9 \%$; $\mathrm{P}=0.001$ ). consanguineous parental marriage was associated with a 3.2-fold increase in the risk of retinopathy in the preterm infants of our study (OR $=2.263$, 95\% CI: $1.240-4.130, \mathrm{P}=0.008$ ). In general, due to the fact that consanguineous marriage is rare or even prohibited in most Western countries, therefore, no study has been conducted in this regard in these countries.

In countries where consanguineous marriage is common, there are few studies that have assessed this issue, among which, Naderian et al. (2010) in Isfahan reported no significant relationship between the consanguineous parental marriage and ROP, which is contrary to our findings, ${ }^{4}$ but a study by Gharaibeh et al. (2011) in Jordan, similar results were reported, where the frequency of consanguineous marriage was higher among ROP than premature infants who did not have retinopathy ( $19.2 \%$ vs $1.9 \%$; $\mathrm{p}=0.007) .{ }^{25}$ There is some indirect evidence for the influence of genetic components on the pathogenesis of ROP along with several other risk factors that have been proposed in various studies for this disease.for example, the prevalence of the disease has been reported to be more common in whites than in blacks or in boys more than girls. ${ }^{16,26}$ It is thought that certain genetic polymorphisms may be due to the function of genes such as vascular endothelial growth factor (VEGF), which control retinal vascularization, and thus be involved in the pathogenesis of ROP. ${ }^{27,28}$ Due to the small number of studies in this field, more studies are needed.

The results of the present study also showed that out of 107 premature infants with retinopathy, 23 infants (21.5\%) needed treatment and the disease had spontaneous recovery in the remaining infants $(5.8 \%$ of all infants needed treatment). The need for treatment among premature infants with retinopathy in the study of Kossambe et al. (2019) in India was 38.7\%, followed by $36.4 \%$ in Portugal and $31.1 \%$ in Mexico, which are higher than our study. ${ }^{11,13,17}$ However, the need for treatment among infants with ROP in a study in the United States was 3.8\% and $17 \%$ in a study in Australia, which is less than the present study. ${ }^{12,29}$ Differences in disease severity in the studied samples could be the reason for the differences in various studies.

\section{Limitations and strengths of the study}

The most important limitation of the present study was the collection of some data from the neonatal hospital record, so some factors such as the concentration and duration of oxygen therapy, that were reported in other studies as a risk factor for ROP, were not available to researchers. Among the strengths of the present study is the relatively high sample size compared to previous studies and retinal examinations with indirect ophthalmoscopy by only one experinced ophthalmologist. The present study was the first study of its kind in Ardabil province, Iran.

\section{Recommendations}

1. Timely retinal examination in all premature infants, especially those at higher risk (i.e. infants weighing less than $1725 \mathrm{~g}$ at birth, infants less than 32.5 weeks gestational age at birth, or consanguineous marriage) is advised.

2. preventive measures for increasing gestational age and birth weight may help reduce the incidence of ROP.

3. Studies with prospective and longitudinal design should be performed by considering more variables that affect the ROP.

In conclusion, the findings of the present study showed that a quarter of preterm infants had retinopathy, birth weight less than 1725 g, gestational age less than 32.5 weeks at birth, and familial marriage were risk factors for ROP. One-fifth of infants with retinopathy needed treatment. Therefore, pediatricians and ophthalmologists need to be warned of the importance of prevention through screening and accurate assessment of ROP.

\section{List of acronyms}

NICU - - Neonatal Intensive Care Unit

ROC - receiver operating characteristic

ROP - retinopathy of prematurity

VEGF - vascular endothelial growth factor

\section{Authors' contributions}

HO, YF, NM, FA: conception, design, drafting of the manuscript, analysis and interpretation of the data, critical review and final approval of the version to be published.

\section{Acknowledgments}

None.

\section{Funding}

This research did not receive any specific grant from funding agencies in the public, commercial, or not-forprofit sectors.

\section{Conflict of Interest}

The authors declare no competing interests. 


\section{Ethical Publication Statement}

We confirm that we have read the Journal's position on issues involved in ethical publication and affirm that this report is consistent with those guidelines.

\section{Corresponding Author}

Habib Ojaghi, Department of Surgery, School of Medicine and Allied Medical Sciences, Imam Reza Hospital, Ardabil University of Medical Sciences, Ardabil, Iran.

ORCID iD: 0000-0002-8372-2185

E-mail: habibojaghi@yahoo.com

E-mails and ORCID iD of co-authors

Yousef Fekri: youseffekri12345@gmail.com

ORCID iD: 0000-0002-5774-265X

Neda Momeni: nedamomeni123@gmail.com

ORCID iD: 0000-0001-8981-2387

Firouz Amani: biostat.f@gmail.com

ORCID iD: 0000-000-0989-1052

\section{References}

1. Mansouri M, Kadivar M, Karkhaneh R, Riazi Esfahani M, Nili Ahmadabadi M, Faghihi H, Mirshahi A, Sadat-Nayeri F, Farahvash MS, Tabatabaei A, Adelpour A, Abdollahi M. Prevalence and risk factors of retinopathy of prematurity in very low birth weight or low gestational age infants. BINA Journal of Ophthalmology. 2007;12(4):428-34.

2. Alizadeh Y, Zarkesh M, Moghadam RS, Esfandiarpour B, Behboudi H, Karambin MM, Heidarzade A. Incidence and Risk Factors for Retinopathy of Prematurity in North of Iran. J Ophthalmic Vis Res. 2015 Oct-Dec;10(4):424-8. doi: 10.4103/2008-322X.176907.

3. Naderian $G$, Iranpour $R$, Mohammadizadeh $M$, Najafabadi FF, Badiei Z, Naseri F, Naderian MA, Sajadi V. The Frequency of Retinopathy of Prematurity in Premature Infants Referred to an Ophthalmology Clinic in Isfahan. J Isfahan Med Sch. 2011;29(128):1-5. [Persian].

4. Naderian GA, Moulavi H, Hadipour M, Sajadi V. Prevalence and risk factors for retinopathy of prematurity in Isfahan. Bina Journal of Ophthalmology. 2010;3(15):208-12.

5. Sadegji K, Hashemi F, Heidarzadeh M, Parish M. Frequency and Risk Factors of Retinopathy of Premature Infants. Medical Journal of Tabriz University of Medical Sciences. 2009;30(2):73-7.

6. Blencowe H, Lawn JE, Vazquez T, Fielder A, Gilbert C. Preterm-associated visual impairment and estimates of retinopathy of prematurity at regional and global levels for 2010. Pediatr Res. 2013 Dec;74 Suppl 1(Suppl 1):35-49. doi: 10.1038/pr.2013.205.

7. Norinia R, Nazari R. Retinopathy of Prematurity: Evolving Concepts in Diagnosis and Management.
Bina Journal of Ophthalmology. 2017;21(4):42130.

8. Kim SJ, Port AD, Swan R, Campbell JP, Chan RVP, Chiang MF. Retinopathy of prematurity: a review of risk factors and their clinical significance. Surv Ophthalmol. 2018 Sep-Oct;63(5):618-637. doi: 10.1016/j.survophthal.2018.04.002. Epub 2018 Apr 19.

9. Roohipoor R, Riazi Esfahani H, Seniar K, Karkhaneh R, Zarei M, Bazvand F. Retinopathy of Prematurity-A Review Article. Bina J Ophthalmol. 2018;24(1):1-19.

10. Chedid F, Shanteer S, Haddad H, Musharraf I, Shihab Z, Imran A, Adma HA, Salman N, Rahmani A. Short-term outcome of very low birth weight infants in a developing country: comparison with the Vermont Oxford Network. J Trop Pediatr. 2009 Feb;55(1):15-9. doi: 10.1093/tropej/fmn064. Epub 2008 Jul 23.

11. Kossambe S, Joglekar S, D’Lima A, Silveira M.P. Incidence and risk factors of retinopathy of prematurity in Goa, India: a report from tertiary care centre. 2019;6(3):1228.

12. Ludwig CA, Chen TA, Hernandez-Boussard T, Moshfeghi AA, Moshfeghi DM. The Epidemiology of Retinopathy of Prematurity in the United States. Ophthalmic Surg Lasers Imaging Retina. 2017 Jul 1;48(7):553-562. doi: 10.3928/23258160-201706 30-06.

13. Acevedo-Castellón R, Ramírez-Neria P, GarcíaFranco R. Incidence of retinopathy of prematurity type 1 and type 2 in a regional Hospital of Social Security in the state of Queretaro, Mexico (20172018). 2019;19(1):91.

14. Reyes ZS, Al-Mulaabed SW, Bataclan F, Montemayor C, Ganesh A, Al-Zuhaibi S, et al. Retinopathy of prematurity: revisiting incidence and risk factors from Oman compared to other countries. 2017;10(1):26.

15. Hadi AMA, Hamdy IS. Correlation between risk factors during the neonatal period and appearance of retinopathy of prematurity in preterm infants in neonatal intensive care units in Alexandria, Egypt. Clinical ophthalmology. 2013;7(1):831-8.

16. Ali M, Anwar M, Naeem M. Retinopathy of prematurity (ROP); association with risk factors of retinopathy of prematurity (ROP) of in-hospital newborns of low birth weight (lbw) in tertiary care hospital. Professional Med J. 2019;26(4):669-73.

17. Coutinho I, Pedrosa C, Mota M, Azeredo-Lopes S, Santos C, Pires G, Teixeira S, Cunha M. Retinopathy of prematurity: results from 10 years in a single neonatal intensive care unit. Journal of Pediatric and Neonatal Individualized Medicine 2017;6(1):e060122doi: 10.7363/060122.

18. Al Hazzani F, Al-Alaiyan S, Hassanein J, Khadawardi E. Short-term outcome of very lowbirth-weight infants in a tertiary care hospital in 
Saudi Arabia. Ann Saudi Med. 2011 NovDec;31(6):581-5. doi: 10.4103/0256-4947.87093.

19. Daraie G, Nooripoor S, Ashrafi A M, Ghorbani R. Incidence of retinopathy of prematurity and some related factors in premature infants born at Amir-alMomenin hospital in Semnan, Iran. KOOMESH. 2016; 17(2): 297-303.

20. Fouladinejad $M$, Motahari MM, Gharib $\mathrm{MH}$, Sheishari F, Soltani M. The prevalence, intensity and some risk factors of retinopathy of premature newborns in Taleghani Hospital, Gorgan, Iran. J Gorgan Univ Med Sci. 2009;11(2):51-4.

21. Ebrahim M, Ahmad RS, Mohammad M. Incidence and risk factors of retinopathy of prematurity in Babol, North of Iran. Ophthalmic Epidemiol. 2010 Jun;17(3):166-70. doi: 10.3109/0928658100373 4860 .

22. Karkhaneh R, Mousavi SZ, Riazi-Esfahani M, Ebrahimzadeh SA, Roohipoor R, Kadivar M, Ghalichi L, Mohammadi SF, Mansouri MR. Incidence and risk factors of retinopathy of prematurity in a tertiary eye hospital in Tehran. Br J Ophthalmol. 2008 Nov;92(11):1446-9. doi: 10.1136/bjo.2008.145136. Epub 2008 Aug 26.

23. Ghaseminejad A, Niknafs P. Distribution of retinopathy of prematurity and its risk factors. Iran J Pediatr. 2011 Jun;21(2):209-14..

24. Mansouri M, Kadivar M, Karkhaneh R, Riazi Esfahani M, Nili Ahmadabadi P. Prevalence and Risk Factors of Retinopathy of Prematurity in Very Low Birth Weight or Low Gestational Age Infants. Bina J Ophthalmol. 2007;12(4):428-34.
25. Gharaibeh A, Khassawneh M, Khriesat W, Alkhatib S, Migdadi Y. Adopting Western Retinopathy of Prematurity Screening Programs in Eastern Countries, are we Screening Properly? Middle East Afr J Ophthalmol. 2011 Jul;18(3):209-13. doi: 10.4103/0974-9233.84047

26. Sabri K, Manktelow B, Anwar S, Field D, Woodruff G. Ethnic variations in the incidence and outcome of severe retinopathy of prematurity. Can J Ophthalmol. 2007 Oct;42(5):727-30. doi: 10.3129/i07-136.

27. Dickinson JL, Sale MM, Passmore A, FitzGerald LM, Wheatley CM, Burdon KP, Craig JE, Tengtrisorn S, Carden SM, Maclean H, Mackey DA. Mutations in the NDP gene: contribution to Norrie disease, familial exudative vitreoretinopathy and retinopathy of prematurity. Clin Exp Ophthalmol. 2006 Sep-Oct;34(7):682-8. doi: 10.1111/j.1442-9071.2006.01314.x.

28. Kwinta P, Bik-Multanowski M, Mitkowska Z, Tomasik T, Pietrzyk JJ. The clinical role of vascular endothelial growth factor (VEGF) system in the pathogenesis of retinopathy of prematurity. Graefes Arch Clin Exp Ophthalmol. 2008 Oct;246(10):1467-75. doi: 10.1007/s00417-0080865-9. Epub 2008 Jun 11.

29. Gunn DJ, Cartwright DW, Gole GA. Prevalence and outcomes of laser treatment of aggressive posterior retinopathy of prematurity. Clin Exp Ophthalmol. 2014 Jul;42(5):459-65. doi: 10.1111/ceo.12280. Epub 2014 Jan 23.

Submission: August 27, 2021

Revision submitted: October 5, 2021 Accepted for publication: October 5, 2021 